\title{
OS DESAFIOS DIAGNÓSTICOS DA INCONTINÊNCIA FECAL
}

DESCRITORES - Incontinência fecal, diagnóstico. Manometria. Defecação, fisiologia. Eletrofisiologia.

Neste número, os ARQUIVOS de GASTROENTEROLOGIA publicam o trabalho de CARVALHO et al. ${ }^{(1)}$, enfocando a incontinência fecal e a aplicação dos métodos manométricos e do estudo do tempo de latência do nervo pudendo (TLNP).

Ao consultarmos as referências bibliográficas do estudo, observamos que não há nenhuma referência nacional sobre o assunto. Com isso, ficamos felizes em poder publicar artigo original produzido por centro brasileiro.

O método de estudo do TLNP é realizado há cerca de 10 anos e seus resultados ainda geram polêmica, pois tem pouca reprodutibilidade e suas aplicações clínicas estão limitadas. Talvez exija que populações maiores sejam estudadas, produzindo, assim, resultados mais confiáveis, traduzindo maior correlação de seus resultados com as origens e graus de incontinência.

Já o método manométrico vem progredindo muito nos últimos 5 anos. A uniformização dos equipamentos e das metodologias estão produzindo resultados mais lineares. Antes desta padronização, cada investigador, além de usar equipamentos e sondas diferentes de outros centros, tinha seu próprio ponto de vista concernente à metodologia. Por esta razão, os dados obtidos de diferentes pesquisadores não eram concordantes até há algum tempo.

Fica muito bem definido pelo estudo de CARVALHO et al. (1) que a medida isolada da pressão de repouso do esfíncter, assim como sua extensão, exceto para casos extremos (hipotonia severa ou hipertonia), não é mais parâmetro manométrico aceito para estabelecer o estado da disfunção anorretal.

A manometria anorretal (MAR) permite que haja observação dinâmica dos esfíncteres. Além de equipamento adequado, necessita que profissional sensível ao estado de constrangimento do exame, associe profundo conhecimento da fisiologia da evacuação, assim como atenção à técnica de realização do mesmo.
A anamnese cuidadosa interpreta algumas causas da incontinência ou da obstipação. Porém, por vezes, não se consegue estabelecer a etiologia da disfunção, sendo necessários métodos diagnósticos, tais como a MAR, o TLNP, a defecografia, o enema opaco, o ultra-som endoanal, a ressonância nuclear magnética e a endoscopia. No nosso meio há falta de centros especializados e pode-se contar com, talvez, não mais de 15 laboratórios de fisiologia anorretal, sendo a maioria ligados à universidades. Nos últimos 5 anos estes centros têm desenvolvido mais estudos e acredita-se que nesta década haverá maior disponibilidade destes fisiologistas para os pacientes.

A incontinência anal é manifestação crescente, em incidência a partir dos 40 anos. De maneira geral, há muita dificuldade para o paciente expressar seus sintomas e, com freqüência, afastam-se do convívio social, do relacionamento com o parceiro e, habitualmente, sofrem de depressão.

Temos a oportunidade de trabalhar na região em que se concentra a maior população do Brasil e que possui os mais avançados centros diagnósticos. Há, porém e de fato, muito desconhecimento quanto a esses meios e às possibilidades de terapêutica das disfunções anorretais. Médicos e pacientes precisam ser melhor esclarecidos. Uma vez estabelecida a causa, como na maioria das doenças, fica facilitado o caminho da cura.

O trabalho de CARVALHO et al..$^{(1)}$, embora realizado com pequena casuística, corresponde à maioria dos achados da literatura atual. Permanece controversa a utilidade do TLNP e a correlação de seus achados com o estado do grau da disfunção. Como os próprios autores citam, talvez seja mais importante observar o tempo de sustentação da contração, do que sua força isoladamente. Como todo músculo esquelético, o esfíncter externo e os elevadores do ânus têm tônus de repouso e sua eficiência muscular para contenção do conteúdo retal reside na dependência de vários fatores. 
A percepção do conteúdo retal se faz pelo mecanismo de distensão dos plexos submucosos no reto. Um arco reflexo determina o relaxamento do esfíncter interno (musculatura lisa) e, ao mesmo tempo, a mensagem é enviada ao córtex cerebral que, uma vez interpretada, envia o comando para impedir a saída do conteúdo (contração) ou para facilitar, com aumento da prensa abdominal, vencendo assim, a barreira imposta pela pressão de repouso do esfíncter externo e dos elevadores do ânus.

As possibilidades de haver interferência da percepção do conteúdo retal, então, são muito vastas: vão desde lesões locais, passando por lesões das vias aferentes e eferentes, além do sistema de cognição pelo córtex cerebral. Incontinência por lesões traumáticas dos músculos, pós-cirurgias, por exemplo, são de forma mais simples diagnosticadas, como vimos no trabalho de CARVALHO et al. ${ }^{(1)}$, muitas vezes somente pelo toque retal.

Um dos parâmetros medidos no trabalho em questão - a sensibilidade retal - é de interpretação extremamente subjetiva e deve ser considerado com reserva, da mesma forma que a pressão esfincteriana de repouso. O reflexo evacuatório no adulto e no idoso é resultado de anos de condicionamento e os valores da normalidade podem ser imprecisos. Em nosso laboratório, por inúmeras vezes, repetimos o teste em um mesmo paciente e os limiares da primeira sensação, da sensação evacuatória constante e o volume máximo tolerado, são díspares e não se correlacionam com o estado de disfunção esfincteriana em boa parte dos doentes. Serão necessários estudos epidemiológicos mais amplos, que levem em consideração fatores ambientais, método de pesquisa, hábitos alimentares e evacuatórios para se poder estabelecer os parâmetros de normalidade.

O trabalho apresentado demonstra claramente que a incontinência é manifestada mais freqüentemente em mulheres. Será que esta prevalência é maior pelo fato destas terem menores bloqueios de verbalizar suas dificuldades nesta área? De qualquer forma, os autores observaram que a incidência aumenta com a idade, dado concordante com a maioria dos trabalhos já realizados.

A contribuição mais importante dos autores é trazer à discussão o tema da incontinência anal. As possibilidades da manometria e do TLNP como métodos de avaliação são inúmeras e devem ser consideradas. O trabalho serve de estímulo para que outros centros no Brasil publiquem e divulguem seus resultados, além de possibilitar novas linhas de pesquisa.

Parabenizamos CARVALHO e seus colaboradores pela pesquisa e desejamos que possam ampliá-la, podendo obter maior significância de seus resultados.

Ricardo Guilherme VIEBIG*

Viebig RG. The diagnostic challenges in fecal incontinence. Arq Gastroenterol 2002;39(3):137-138.

HEADINGS - Fecal incontinence, etiology. Manometry. Defecation, physiology. Electrophysiology.

\section{REFERÊNCIA BIBLIOGRÁFICA}

1. Carvalho LP, Corleta OC, Mallmann ACM, Koshimizu RT, Spolavori A. Neuropatia pudenda: correlação com dados demográficos, índice de gravidade e parâmetros pressóricos em pacientes com incontinência fecal. Arq Gastroenterol 2002;39:139-146.

* MODINE - Laboratório de Motilidade Digestiva e Neurogastroenterologia, São Paulo, SP. 